\title{
Current Guidelines for Obesity Prevention in Childhood and Adolescence
}

\author{
Susann Weihrauch-Blüher ${ }^{a, b} \quad$ Kartin Kromeyer-Hauschild $^{c} \quad$ Christine Graf $^{d}$ \\ Kurt Widhalm ${ }^{\mathrm{e}} \quad$ Ulrike Korsten-Reck ${ }^{f} \quad$ Birgit Jödickeg Jana Markert ${ }^{\mathrm{a}}{ }^{\mathrm{h}}$ \\ Manfred James Müller ${ }^{i, j}$ Anja Moss ${ }^{j}$ Martin Wabitsch ${ }^{j}$ \\ Susanna Wiegandg
}

aIFB AdiposityDiseases; Leipzig University Medical Center, University of Leipzig, Leipzig,Germany; ${ }^{b}$ Department of Pediatrics I / Pediatric Endocrinology and Diabetology, University Hospital of Halle/Saale, Halle/Saale, Germany; ' Institute of Human Genetics, Jena University Medical Center, Friedrich-Schiller-University of Jena, Jena, Germany; ${ }^{d}$ Institute of Movement and Neuroscience, German Sport University of Cologne, Cologne, Germany; ${ }^{e}$ Department Of Clinical Nutrition and Prevention, Children's Hospital, University Hospital of Vienna, Vienna, Austria; ${ }^{\mathrm{f}}$ Department of Rehabilitative and Preventive Sports Medicine, University Medical Center Freiburg, Freiburg i.Br., Germany; ${ }^{9}$ Department of Pediatric Endocrinology and Diabetology and Center for Social-Pediatric Care, Charité Universitätsmedizin Berlin, Berlin, Germany; ${ }^{h}$ Institute of Special and Inclusive Education, University of Leipzig, Leipzig, Germany; ${ }^{i}$ Institute for Human Nutrition and Food Sciences, Christian-Albrechts University, Kiel, Germany; ${ }^{j}$ Department of Pediatric Endocrinology and Diabetology, Hospital for Children and Adolescents, University of Ulm, Ulm, Germany

\section{Keywords}

Childhood obesity · Behavior-oriented prevention · Community-based prevention · Lifestyle · Randomized controlled trials

\section{Abstract}

Objective: Current guidelines for prevention of obesity in childhood and adolescence are discussed. Methods: A literature search was performed in Medline via PubMed, and appropriate studies were analyzed. Results: Programs to prevent childhood obesity have so far remained mainly school-based and effects have been limited. Analyses by age group show that prevention programs have the best results in younger children ( $<12$ years). Evidence-based recommendations for pre-school- and early school-aged children indicate the need for interventions that address parents and teachers alike. During adolescence, school-based interventions 
proved most effective when adolescents were addressed directly. To date, obesity prevention programs have mainly focused on behavior-oriented prevention. Recommendations for community- or environment-based prevention have been suggested by the German Alliance of Noncommunicable Diseases and include a minimum of $1 \mathrm{~h}$ of physical activity at school, promotion of healthy food choices by taxing unhealthy foods, mandatory standards for meals at kindergartens and schools as well as a ban on unhealthy food advertisement aimed at children. Conclusion: Behavior-oriented prevention programs showed only limited long-term effects. Certain groups at risk for the development of obesity are not reached effectively by current programs. Although universally valid conclusions cannot be drawn given the heterogeneity of available studies, clearly combining behavior-based programs with communitybased prevention to counteract an 'obesogenic environment' is crucial for sustainable success of future obesity prevention programs.

(C) 2018 The Author(s)

Published by S. Karger GmbH, Freiburg

\section{Introduction}

\section{Obesity in Children and Adolescents}

Overweight and obesity in childhood and adolescence has lately developed into a global health issue $[1,2]$. Although an emerging trend suggests a stagnating prevalence of obesity - especially for younger (pre-school) children [3] - for adolescents the prevalence is clearly still increasing [4]. The incidence of cardiometabolic comorbidities [5-9] is considerably higher for obese teens, and a special risk factor seems to be the presence of abdominal obesity [10].

Unfortunately, the limited success of conservative therapies $[11,12]$ is reflected in the accessible weight loss, which has been determined as 0.05-0.42 BMI-SDS units (standard deviation score of the body mass index) over 12-24 months. The success rate clearly correlates with age: younger kids have a better outcome [11, 13].

\section{Types and Objectives of Prevention}

Interventions in health promotion and prevention aim to avoid diseases and maintain health. A WHO (World Health Organization) classification distinguishes between general, selective, and targeted intervention (table 1). Prevention programs can be classified as behavior-oriented (individual-based intervention) or community-/environment-based (context-related intervention) (table 1). The latter supports the implementation of healthrelevant decision-making; environmental factors, like residential neighborhood, can positively influence not only weight status but also health-related behavior [14, 15]. Current prevention approaches have focused mainly on behavioral interventions, while current gaps in obesity prevention lie mainly in the area of community-/environment-based interventions. Up to now, only a few precise interventions have studied the effects and influences of the (social) environment on long-term weight development [16].

\section{Aim of This Study}

The objective of this paper is to summarize and to discuss internationally available guidelines, recommendations, and prevention strategies for obesity prevention in childhood and adolescence.

More specifically, current recommendations for behavior-oriented prevention as well as community-/environment-based prevention of obesity in childhood and adolescence are outlined below, based on the current state of international studies. 
Weihrauch-Blüher et al.: Current Guidelines for Obesity Prevention in Childhood and Adolescence

Table 1. Types of prevention

\begin{tabular}{|c|c|c|}
\hline Types of prevention & Target & Measures \\
\hline $\begin{array}{l}\text { General prevention } \\
\text { (primary prevention) }\end{array}$ & $\begin{array}{l}\text { Target group: } \\
\text { General public } \\
\text { Target: } \\
\text { Counteracting the } \\
\text { development of obesity }\end{array}$ & $\begin{array}{l}\text { Creating awareness of obesity as an illness } \\
\text { Establishing healthy surroundings (e.g. health- } \\
\text { promoting school environments) } \\
\text { Education and behavioral training in day care } \\
\text { centers, schools and through mass media } \\
\text { Improving physical activity opportunities in schools } \\
\text { and communities } \\
\text { Health orientation in politics (e.g. economic and } \\
\text { agriculture policies) } \\
\text { Removal of advertising in children's TV } \\
\text { programming } \\
\text { Cooperation of interest groups (e.g. food industries, } \\
\text { health insurances, media and sport clubs) }\end{array}$ \\
\hline $\begin{array}{l}\text { Selective prevention } \\
\text { (secondary prevention) }\end{array}$ & $\begin{array}{l}\text { Target group: } \\
\text { Potentially at-risk group } \\
\text { of general public } \\
\text { Target: } \\
\text { Obesity prevention along } \\
\text { with the prevention of } \\
\text { associated comorbidities }\end{array}$ & $\begin{array}{l}\text { Early identification of and discussion with at-risk } \\
\text { individuals through pediatricians and family } \\
\text { doctors or physicians at public health offices } \\
\text { Routine checkups for the purpose of offering and } \\
\text { including in family-oriented training programs }\end{array}$ \\
\hline $\begin{array}{l}\text { Targeted prevention } \\
\text { (tertiary prevention) }\end{array}$ & $\begin{array}{l}\text { Target group: } \\
\text { Overweight children and } \\
\text { adolescents with high } \\
\text { health risks or already } \\
\text { obese } \\
\text { Target: Weight } \\
\text { stabilization and } \\
\text { improvement of } \\
\text { comorbidities }\end{array}$ & $\begin{array}{l}\text { Interdisciplinary programs and measures (see } \\
\text { recommendations under primary and secondary } \\
\text { prevention) } \\
\text { Support through the above-mentioned measures } \\
\text { for general obesity prevention as well as measures } \\
\text { of general health promotion }\end{array}$ \\
\hline
\end{tabular}

Within the scope of the prevention offerings will be differentiated between:

Behavior-oriented Personalized measures: Education in nutrition

prevention Addressing individual Promotion of movement during school lessons as behavior and habits well as educational programs for enhancing physical activities

Community-/ environment-based prevention
Context related measures: Provision of facilities and equipment in the school Facilitating health-related environment (e.g. playgrounds, healthy school meals decision making and snacks)

\section{Material and Methods}

This paper is based on a literature search in Medline via PubMed and targeted scientific papers that describe the effects of different strategies for the prevention of obesity in children and adolescents. Key search terms used were: obesity AND/OR prevention AND/OR childhood AND/OR adolescence AND/OR randomized clinical trial AND/OR review. A total of 1,509 papers were found, 95 of which were randomizedcontrolled studies. Results of the relevant studies, as well as the resulting recommendations, are outlined in a shortened version below. 
Weihrauch-Blüher et al.: Current Guidelines for Obesity Prevention in Childhood and Adolescence

\section{Behavior-Based Prevention}

\section{Age-Specific, Evidence-Based Interventions}

Prevention programs for children have a more positive effect on the BMI if the children are younger: the best effects could be shown in children aged 6-12 years.

This conclusion can be drawn from a meta-analysis in which 37 controlled (randomized and non-randomized) studies (27,946 participants) were included with the minimal intervention duration of 12 weeks [13]. The mean BMI-SDS decrease for the participants of the intervention group was $0.15 \mathrm{~kg} / \mathrm{m}^{2}$ [13]. Given the large heterogeneity of the studies in terms of study design, type and duration of the intervention, primary and secondary endpoints as well as length of the follow-up period, results are difficult to compare. However, there is nonetheless good evidence for certain intervention procedures. These recommendations are presented for different age groups, settings and intervention approaches in the following.

\section{Infants and Pre-School Children}

General Recommendations

Prevention measures should be addressed to parents (family setting) and/or caregivers in nurseries and kindergartens. The targeted transfer of knowledge to parents and caregivers alongside the optimization of nutritional behavior and physical activity showed the most positive effects on the weight status of children in this age group [17].

Prevention measures that enhance the development of individual competences for healthy food selections and increased physical activity are most beneficial for infants and preschool aged children. Parents and caregivers should serve as positive role models [18]. Within the setting of a nursery, kindergarten or day-care center, measures combining physical activity and optimization of the catering offerings as well as the promotion or modeling of good eating habits have proven most beneficial [18].

The formative experiences of a healthy lifestyle in early childhood ranks as the key factor in the prevention of overweight and obesity. These lifestyle factors also include a varied and balanced diet, regular physical activity, prevention of sedentary behavior (i.e. during media use) and parental abstention from smoking (especially during pregnancy) [19]. Ensuring sufficient sleep and relaxation time, however, also has great significance for the weight development of children. Additionally, advertising of foods especially targeted at pre-school children has a not negligible negative influence. Exposure to (not only) TV advertisements should be limited or completely avoided wherever possible [19].

The findings presented here have been summarized into recommendations for actions to promote the healthy growth and development of infants and pre-school children. They are based on an expert consensus to which numerous scientific societies (German Obesity Society (DAG), Workgroup for Childhood Obesity (AGA), German Nutrition Society (DGE), The Research Institute of Child Nutrition (FKE), and others) have contributed [19]. Detailed recommendations for specialists or parents are summarized in tables 1-4.

\section{Nutrition}

For newborns and infants breastfeeding plays a central role in the prevention of overweight and obesity. A negative correlation between breastfeeding and the manifestation of an impaired glucose tolerance at a later age (as late as adolescence) is well established [2023]. It however remains unclear if the weight status of the breastfeeding mother has an influence on the child's risk of becoming obese or developing metabolic risk factors [21, 22].

A study on the breastfeeding behavior of normal-weight, in contrast to obese, mothers could show that obese mothers breastfeed less frequently and for shorter periods than 
Weihrauch-Blüher et al.: Current Guidelines for Obesity Prevention in Childhood and Adolescence

Table 2. Recommendations for the prevention of obesity and overweight in infants and pre-school children

\begin{tabular}{|c|c|}
\hline Nutrition & $\begin{array}{l}\text { - } \text { By age 1, meals should be taken seated with the family } \\
\text { - } \quad \text { Introduction to new, healthy foods } \\
\text { Positive mealtime conditions (e.g. positive atmosphere, no outside } \\
\text { distractions: e.g. TV) } \\
\text { - Varied diet with plenty of beverages (water or unsweetened, } \\
\text { - } \text { Amgar-free drinks) } \\
\text { - } \text { products) } \\
\text { - } \text { Vimited animal derived products (milk and milk products, fish, eggs) } \\
\text { - Careful observation of the sugar content in food and drinks }\end{array}$ \\
\hline Physical activity and sports & $\begin{array}{l}\text { - For children 3-5 years: at least } 60 \text { min of structured physical activity } \\
\text { daily } \\
\text { - } \geq 3 \text { years: From } 60 \text { min to several hours of unstructured physical } \\
\text { activity; limit inactivity to less than } 60 \text { minutes at a time, outside of } \\
\text { sleep } \\
\text { - School age: a minimum of } 60 \text { min of moderate to intensive physical } \\
\text { activity daily or at least } 10,000 \text { steps per day } \\
\text { - Adolescence: a minimum of } 90 \text { min of moderate to intense physical } \\
\text { - activity daily or at least } 10,000 \text { steps per day } \\
\text { Acquisition of basic motor skills as the basis for future physical } \\
\text { - dexterity and activity } \\
\text { Promoting access to indoor and outdoor exercise areas } \\
\text { Education of parents and caregivers on the importance of physical } \\
\text { activity }\end{array}$ \\
\hline Media consumption & $\begin{array}{l}\text { - } \\
\text { - Limit access to media and in general reduction of leisure time spent } \\
\text { sitting according to age: } \\
\text { - For children under } 3 \text { years: } 0 \text { min } \\
\text { - For children 3-6 years: } 30 \text { min maximum }\end{array}$ \\
\hline
\end{tabular}

In addition: interventions as well as targeted education of parents and caregivers.

normal-weight mothers [25]. Possible long-term effects on the weight status of their children however remain unclear.

The scientific societies recommend exclusive breastfeeding for 4-6 months [19].

From the age of 1 year on, children can and should consume their meals at the family table. The nutritional recommendations for the infant and pre-school child include a varied diet with ample beverages (water and unsweetened/sugar-free drinks), ample plant-based foods (vegetables, fruits, whole grain products, potatoes), limited foods of animal origin (milk, milk products, meat, fish, eggs), and a low consumption of sugar and sweets (table 2) [19].

Especially pre-school children should only consume foods and beverages with a low sugar content: The correlation between additional intake of sugar - predominantly in soft drinks - to the development of overweight and obesity has been proven in several studies [25-27].

After the pre-school age, there is a close and direct correlation between the development of obesity and the size of meals and the consumption of unhealthy snacks between meals. Securing healthy eating habits requires introducing new and healthy foods just as much as ensuring the food supply itself [19]. 
Weihrauch-Blüher et al.: Current Guidelines for Obesity Prevention in Childhood and Adolescence

Recommendations for food choice, catering offerings, and further aspects of environmentoriented prevention in day-care centers have been articulated by the German Nutrition Society 2014: (www.fitkid-aktion.de/service/medien.html\#c308).

Physical Activity and Sports

International recommendations on physical activity for children aged 3-5 years suggest at least $60 \mathrm{~min} /$ day of guided physical activity (i.e., supervised by an sport's education or trainer)and children not to remain inactive longer than $60 \mathrm{~min}$ at a time, except when sleeping. At this age, children should be acquiring fundamental motor skills. Caretakers should enhance regular physical activity and offer exercise units regularly [28, 29] (table 2).

\section{Media Consumption}

With every additional hour of TV consumption the obesity prevalence in children increases by $2 \%$ [30]. Daily media consumption can be reduced significantly by prevention measurements targeting access to media. The effects are most prominent in the pre-school group compared to other age groups [31]. The expert consensus for pre-school aged children on media consumption is generally to avoid TV sets and computers in children's bedrooms and to limit media consumption strictly in the first 3 years. Up to 6 years, media consumption should be limited to $30 \mathrm{~min} /$ day maximum [32] (table 2).

\section{School Age}

General Recommendations

School-based prevention programs offer successful approaches to obesity prevention, because of the regular contact between children and teachers. Behavior-oriented prevention measures such as nutritional education and encouraging physical activity within the framework of regular lessons can be easily combined with environment-oriented prevention measures like providing supportive facilities within the school environment (playgrounds, drinking fountains, healthy school meals, and healthy snacks for break times) [27].

While exclusive nutritional interventions or programs solely targeting physical activity show only minor effects in a school setting in terms of a long-term outcome, the combination of both demonstrates a clear effect on weight status [33].

School-based programs offered for more than 1 year have the most beneficial effect on weight status and obesity-relevant behavior. Among the most relevant predictors for a successful therapy are the strong involvement of the parents and, again, the combination of nutritional education with an increase of physical activity [34] (table 3).

The following strategies have been proven most favorable for the school-based intervention for obesity prevention:

- Interventions in schools involving healthy nutritional behavior, physical activity, and self-perception as well as involvement of the parents [33-35]

- Increasing the number of hours for physical education in schools and the development of extensive motor skills starting at a pre-school age [13]

- Improvement of the quality of the catering offerings [13]

- Reducing the consumption of sugared beverages by offering drinking fountains [27].

Nutrition

Nutritional recommendations for school-aged children comprise aspects of a varied diet as previously discussed in the section on infants and pre-school children. Several studies additionally show a close relationship between increased intake of soft drinks, food with a high energy density and/or fast food consumption on the one hand and the development of overweight/obesity on the other [25-27]. Therefore, the consumption of sugared beverages 
Weihrauch-Blüher et al.: Current Guidelines for Obesity Prevention in Childhood and Adolescence

Table 3. Recommendations for prevention of obesity and overweight in early and middle school years

\begin{tabular}{|c|c|}
\hline Nutrition & $\begin{array}{l}\text { Varied, balanced diet: } \\
\text { - } \quad \text { Ample beverages (water or unsweetened, sugar-free drinks) } \\
\text { - } \text { Plentiful varied plant-based foods (vegetables, fruit, whole grain } \\
\text { products, potatoes) } \\
\text { - Limited animal derived products (milk/milk products, meat, fish, } \\
\text { - eggs) } \\
\text { - Very limited sugar and sweets, age adjusted portion sizes } \\
\text { - } \quad \text { Limitation or elimination of sweetened drinks } \\
\text { - Creation of a healthy, balanced school meal program }\end{array}$ \\
\hline Physical activity and sports & $\begin{array}{l}\text { - Daily physical activity of at least } 90 \text { minutes (possible also in } \\
\text { periods of } 15 \text { minutes for endurance and interval training) } \\
\text { - } \text { Minimum of } 12,000 \text { steps per day } \\
\text { - Limit sedentary activity to a maximum of } 2 \mathrm{~h} / \text { day }\end{array}$ \\
\hline Media consumption & $\begin{array}{l}\text { - Limit media consumption as well as sedentary leisure time } \\
\text { according to age: } \\
\text { - For children 7-11 years: } 60 \text { m maximum }\end{array}$ \\
\hline
\end{tabular}

In addition: interventions as well as targeted education of teachers and parents.

should be avoided or at least severely restricted for school-aged children as well. To increase water consumption in elementary schools the 'trinkfit' study combined a behavior-oriented prevention measure (teaching units) with an environment-oriented prevention measure (drinking fountains). Just 1 year after implementation, the risk for overweight in the intervention group was significantly lower than in the control group [27].

In 2014, the DGE (Deutsche Gesellschaft für Ernährung; German Nutrition Society) compiled quality standards for condition-oriented prevention in schools in terms of a balanced catering offering that promotes healthy eating (www.schuleplusessen.de/service/medien. html\#c246). These recommendations however are, so far, not binding in Germany. The link between meal size as well as tendency of between-meal snacking and the development of obesity rises in importance with the increasing age of the children (table 3).

Physical Activity and Sports

For school-aged children, several recommendations for physical activity have been presented by international expert societies and health organizations (World Health Organization (WHO), European Association for the Study of Obesity (EASO), National Institute for Health and Clinical Excellence (NICE)). They suggest, based on current international data, a minimum of $60 \mathrm{~min} /$ day of moderate to intensive physical activity, or at least 10,000 steps/ day [36].

Recommendations for Germany, based on national expert consensus, even go beyond that: school-aged children in Germany should exercise for at least $90 \mathrm{~min} /$ day (for example, several 15 min-periods of continuous activity) or a minimum of 12,000 steps). Additionally, daily routines, like an active method to reach school (e.g. walking or biking), should be encouraged [32] (table 3). 
Weihrauch-Blüher et al.: Current Guidelines for Obesity Prevention in Childhood and Adolescence

Table 4. Recommendations for prevention of obesity and overweight in adolescence

\begin{tabular}{ll}
\hline Nutrition & See recommendations for school-aged children in table 3 \\
\hline Physical activity and sports & See recommendations for school-aged children in table 3 \\
\hline Media consumption & $\begin{array}{l}\text { Limit media consumption as well as sedentary leisure time according to age: } \\
\text { For adolescents age } 12 \text { years and older. } 120 \text { min maximum per day }\end{array}$ \\
\hline
\end{tabular}

In addition: direct transfer of knowledge on obesity related aspects to adolescents.

Media Consumption

The expert consensus for media consumption suggests an age-adapted recommendation for Germany: Up through the age of 11 years, media consumption should be restricted to 60 min/day. After age 12, $120 \mathrm{~min} /$ day should not be exceeded [32] (table 3).

\section{Adolescents}

The targets of intervention for adolescents are also enhancing physical activity, optimizing eating habits, and reducing media consumption (table 4).

The nutritional recommendations listed above for younger ages similarly apply for adolescents. In particular, the intake of sweetened beverages poses an enormous risk factor for developing obesity in this age group: The Dortmund Nutritional and Anthropometric Longitudinally Designed (DONALD) Study examined the relationship between the consumption of soft drinks and weight status over a period of 5 years in German youths. Increased consumption of sweetened beverages (soft drinks and juices) caused a significant increase in the BMI-SDS. This effect was even more clearly visible for girls than for boys [37].

The German expert consensus for adolescents older than 12 years recommends 90 $\mathrm{min} /$ day of physical activity and a maximum of $120 \mathrm{~min} /$ day time spent on media [32].

Studies of prevention measures in this age group showed positive effects with respect to weight and other obesity markers like waist circumference, for interventions containing knowledge transfer along with an interdisciplinary approach.

The direct transfer of knowledge to the adolescents (rather than through parents or teachers as recommended for the younger age groups) seems a promising approach, because of teens' growing autonomy in regard to lifestyle and goal setting. The intrinsic motivation of adolescents also is of great importance, much more than in the younger age groups, where motivation is largely external and driven by parents and teachers [38]. Recommendations for this age group are compiled in table 4.

\section{International Studies on Obesity Prevention in Children and Adolescents}

Infants and Pre-School-Aged Children

So far, only few international studies have focused on prevention in nurseries, kindergartens, and day-care centers for children aged $0-3$ years.

One current systematic review contains only two interventions for the ages of 2-5 years as well as one intervention for children at a mean age of 4.2 years. A total of 15 studies were evaluated, 7 of which reported on a weight status improvement due to the intervention [39].

A meta-analysis of 55 studies on the prevention of obesity in pre-school children could show that the group of 0 - to 5 -year-olds ( 3 of the 55 studies) decreased their BMI by 0.26 $\mathrm{kg} / \mathrm{m}^{2}$. This improvement was clearly higher than the effects seen in school-aged children [13].

Hesketh and Campbell [40] considered 23 studies in a meta-analysis on the prevention of obesity in the age group of 0- to 5-year-olds. The prevention measures here were carried 
out in kindergartens, doctors' offices, other varied settings (taking into account different habitats), and within families. Of these studies, 15 were conducted in the US, 12 focused on socioeconomically disadvantaged families, 14 interventions covered several thematic fields (e.g. reduction of fat intake, physical activity, reduction of sedentary behavior). Interventions varied in length from $2 \times 6 \mathrm{~h}$ to 10 years in one doctor's office). Despite the heterogeneity of the studies, consensus could be reached that preventive measures for the 0 - to 5-year-old children, hence in early childhood development, offer an important chance for the lasting transfer of knowledge and behavior patterns to prevent overweight and obesity.

In particular, the enhancement of fundamental motor skills [41] as well as the reduction of media consumption [31] can be seen as especially effective.

\section{School-Aged Children}

The effect of school-based programs focusing on increasing physical activity were analyzed by Harris et al. [42]. 18 studies with a total of 18,141 children were included. The intervention time ranged between 4 months and 3 years. Neither a considerable reduction of the BMI nor clear results on body composition (body fat, skinfold thickness) could be seen. Interventions including additional components to increase the activity level, however, produced visible improvements in a variety of lifestyle aspects [42]. Da Silveira et al. [43] examined data of 8,722 children in a meta-analysis studying nutritional education in schools. These interventions aimed at preventing or reducing overweight (primary or secondary prevention, respectively), and the length of intervention ranged from 4 months to 3 years. Locations were predominantly classrooms; parents were integrated only in 3 studies. The mean reduction of $\mathrm{BMI}$ was $0.33 \mathrm{~kg} / \mathrm{m}^{2}$. Longer interventions appeared to increase this effect to $0.48 \mathrm{~kg} / \mathrm{m}^{2}$. A beneficial effect from nutritional education alone in a school setting could therefore clearly be demonstrated. Girls profited somewhat more than boys [43].

Another international meta-analysis integrated studies which were conducted in a school setting and aimed at reducing the BMI of school-aged children. 43 studies with a total of 36,579 participants were included. A reduction of the BMI by $0.17 \mathrm{~kg} / \mathrm{m}^{2}$ could be seen. This effect was significantly higher in girls $\left(-0.28 \mathrm{~kg} / \mathrm{m}^{2}\right)$ than in boys $\left(-0.17 \mathrm{~kg} / \mathrm{m}^{2}\right)$. Most successful were the interventions combining physical activity with the optimization of eating habits (BMI reduction by $0.17 \mathrm{~kg} / \mathrm{m}^{2}$ ) [44].

\section{Adolescents}

To date, most prevention programs for adolescents have had a selective interventional approach and target special risk groups or already overweight adolescents in order to prevent continuing weight gain. Six randomized clinical studies were conducted for ages 12 years and older (191-1,560 participants). In 5 of the 6 studies the increase of physical activity was a key component along with the transfer of knowledge in the areas of healthy diets and/or selfefficacy and/or sedentary behavior. One study only focused on food intake and leisure-time behavior.

The results here also differ largely because of the heterogeneity in terms of intervention time and contents: weight status improvement (BMI and/or other anthropometric parameters) were shown for both sexes; however, the intervention time here was very long (maximum 4 years) $[45,46]$. Interventions for obesity prevention in adolescents seem generally more successful with girls [47].

Summarizing the studies for adolescents, positive effects in terms of weight and other parameters of body composition (waist circumference, body fat mass) could be seen when a multi-component approach was used with an interdisciplinary intervention concept using direct transfer of knowledge to the adolescents themselves [38]. 
Weihrauch-Blüher et al.: Current Guidelines for Obesity Prevention in Childhood and Adolescence

\section{Community-/Environment-Based Prevention}

The increasing obesogenic environment is an important reason for the growing obesity epidemic [48]. A longitudinal study has analyzed the effect of several different environmental factors (including social factors) on the risk of childhood obesity. This study was conducted over a 4-year period and included a almost 500 children [49]:

The most important determinants were the length of the street the children lived on, accessibility of the nearest playground by foot, frequency of busses/trains passing the street, as well as the socioeconomic status (SES) of the neighborhood. The SES clearly showed the greatest impact; the BMI-SDS of children living in socioeconomically disadvantaged neighborhoods ranged 0.31 SDS points above the reference group [49].

However, based on a large cross-sectional study with approximately 3,500 adolescents, only $2 \%$ of the BMI variation could be explained by differing characteristics of the residential environment (e.g. population density, traffic density, availability of high-energy food, number of sports and play grounds) [14]. According to the latest data, individual and/or social factors clearly seem to have greater influence on the development of childhood obesity than environmental determinants [49]. There are initial indications that condition-oriented measures are nonetheless a promising approach to obesity prevention in younger children [50]. In a current review on obesity prevention programs focusing on the change of environmental conditions, it could be shown that these changes can lead to the enhancement of physical activity or weight-related parameters.

However, only 14 of the over 300 studies analyzed in this review targeted a change in living conditions (such as accessibility to playgrounds, optimization of school catering offerings, etc.). Given this small number of studies, it is too early to draw conclusions on the individual effect of changes in environmental conditions [51].

Recommendations for Community-/Environment-Based Prevention of the German Alliance of Noncommunicable Diseases

The German Alliance of Noncommunicable Diseases has, in agreement with the Global Action Plan for the prevention and control of noncommunicable diseases of the WHO, recommended the following measures which can only be implemented with the support of political decision-makers, but are seen as essential for the realization of a sustainable success in fighting the obesity epidemic [52]:

- Schools must offer a minimum of 60 min of daily physical activity/sports

- Implementation of a sugar tax / fat tax

- Development of binding quality standards for the catering offers in kindergartens and schools

- Ban of advertisement for unhealthy food targeted at children.

A combination of behavior-oriented and community-/environment-based preventive measures which support a health-promoting lifestyle and living environment right from the beginning can ensure better results in the long run than behavior-oriented preventive measures alone. The combination of both approaches can reach all social groups and genders equally [52].

\section{Discussion}

Current prevention strategies for childhood overweight and obesity are insufficient and so far at least partially inadequate in most countries.

Community-/environment-based preventive approaches outlined above are necessary. However, they cannot counteract the obesity epidemic alone in our complex obesogenic envi- 
Weihrauch-Blüher et al.: Current Guidelines for Obesity Prevention in Childhood and Adolescence

ronment. Implementation of the measures listed above requires healthy living spaces like nearby playgrounds and parks for children and adolescents, freely available drinking fountains in day-care centers and schools, binding quality standards for catering offerings in kindergartens and schools, and other measures of environment-oriented prevention.

Given the data for the prevention of obesity compiled above, the pediatrician, general practitioner, and physician in the public health services all have an important role to play along with other professions: The physician (or nurses) is in direct contact with parents and children and thus has the opportunity to monitor (weight) development continuously and analyze possible causes. This access requires that physicians are sufficiently aware of obesityrelated issues. Physicians and health professionals should provide families with information and offer support. Staff of pediatric medical care facilities should have knowledge of (better yet information material on) secondary and tertiary prevention offers in the vicinity. Certified offers for tertiary obesity prevention in Germany are listed, for example, on the homepage of the Arbeitsgemeinschaft Adipositas im Kindesalter (AGA).

A physician's awareness of obesity provides the vital opportunity to link preventive measures of teachers, nutritional experts, and trainers of physical activities. Authorities responsible for health and health education can also be contacted and involved by the physician, if necessary.

Since preventive measures are all the better if implemented early in life, early detection of childhood overweight or obesity by physicians is of the utmost importance. Therefore, obesity and its prevention should be a significant topic in medical education and training.

The specific physician"s role in prevention of childhood obesity incudes:

- Identification of children at risk, e.g. by routinely repeated calculation of the BMI and measurement of waist circumference

- Diagnosis and possible therapy of comorbidities or transfer to a specialized medical facility

- Discussion of the problem with parents or legal guardians

- Key role in distributing offers of selective and targeted prevention and early transfer of affected children into appropriate interdisciplinary therapy programs

- Informing the appropriate committees (medical associations, health authorities) where regional offerings are lacking and drawing their attention to local needs.

Anthropometric parameters like BMI and waist circumference should be calculated and measured regularly by pediatricians and physicians and become a fixed component of nursery- or school-entry examination. Age- and gender-specific reference values are meanwhile available for most countries [53, 54].

Finally, pediatricians, general practitioners, and physicians in public health services provide a crucial link between public health strategies and the individual families and should all be aware of the recommendations for community-/environment-based prevention of the German Alliance of Noncommunicable Diseases (see above). All of these recommendations should be communicated by physicians to broad levels of the population to facilitate their implementation [52].

\section{Conclusions}

As prevention strategies for overweight and obesity in childhood and adolescence are insufficient in most countries to date and at least partially inadequate, a rethinking and revision of available guidelines and recommendations is mandatory.

Community-/environment-based preventive approaches as outlined above are urgently needed. However, they cannot counteract the obesity epidemic alone in our complex obeso- 
genic environment. Implementation of the measures listed above requires healthy living spaces, e.g. nearby playgrounds and parks for children and adolescents, freely available drinking fountains in day-care centers and schools, binding quality standards for catering offerings in kindergartens and schools, and other measures of environment-oriented prevention.

The meta-analyses' conclusions make these educational and health policy decisions, and the subsequent resulting activities, absolutely vital. In the prevention of obesity, political decision-makers must be involved in order to establish and finance comprehensive, interconnected support systems for the behavior-based and community-/environmental based prevention of obesity.

\section{Disclosure Statement}

The authors declare no conflict of interest.

\section{References}

1 Han J, Lawlor D, Kimm S: Childhood obesity. Lancet 2010;375:1737-1748.

2 World Health Organization: Obesity and Overweight. 2017. http://www.who.int/en/news-room/fact-sheets/ detail/obesity-and-overweight. (last accessed June 12, 2018).

-3 Olds T, Maher C, Zumin S, et al: Evidence that the prevalence of childhood overweight is plateauing: data from nine countries. Int J Pediatr Obes 2011;6:342-360.

4 Blüher S, Meigen C, Gausche R, et al: Age-specific stabilization in obesity prevalence in German children: A cross-sectional study from 1999 to 2008. Int J Pediatr Obes 2011;6 e199-206.

5 Holl R, Hoffmeister U, Thamm M, et al: Does obesity lead to a specific lipid disorder? Analysis from the German/ Austrian/Swiss APV registry. Int J Pediatr Obes 2011;6:53-58.

6 Patel D, Srinivasan S, Xu J, et al: Persistent elevation of liver function enzymes within the reference range is associated with increased cardiovascular risk in young adults: the Bogalusa Heart Study. Metabolism 2007; 56:792-798

7 Pervanidou P, Akalestos A, Bastaki D, et al: Increased circulating high-sensitivity Troponin T concentrations in children and adolescents with obesity and the metabolic syndrome: a marker for early cardiac damage? Metabolism 2013;62:527-531.

8 Wiegand S, Keller K, Röbl M, et al: Obese boys at increased risk for nonalcoholic liver disease: evaluation of 16,390 overweight or obese children and adolescents. Int J Obes (Lond) 2010;34:1468-1474.

-9 Zimmet P, Alberti G, Kaufman F, et al: The metabolic syndrome in children and adolescents. Lancet 2007;369: 2059-2061.

10 Blüher S, Molz E, Wiegand S, et al: Body mass index, waist circumference, and waist-to-height ratio as predictors of cardiometabolic risk in childhood obesity depending on pubertal development. J Clin Endocrin Metab 2013; 98:3384-3393.

11 Mühlig Y, Wabitsch M, Moss A, et al: Weight loss in children and adolescents. Dtsch Arztebl Int 2014;111: 818-824.

12 Oude Luttikhuis H, Baur L, Jansen H, et al: Interventions for treating obesity in children. Cochrane Database Syst Rev 2009;1:CD001872.

13 Waters E, de Silva-Sanigorski A, Hall B, et al: Interventions for preventing obesity in children. Cochrane Database Syst Rev 2011;12:CD001871.

14 Lange D, Wahrendorf M, Siegrist J, et al: Associations between neighbourhood characteristics, body mass index and health-related behaviours of adolescents in the Kiel Obesity Prevention Study: a multilevel analysis. Eur J Clin Nutr 2011;65:711-719.

15 Ludwig J, Sanbonmatsu L, Gennetian L, et al: Neighborhoods, obesity, and diabetes-a randomized social experiment. N Engl J Med 2011;365:1509-1519.

16 Plachta-Danielzik S, Kehden B, Landsberg B, et al: Attributable risks for childhood overweight: evidence for limited effectiveness of prevention. Pediatrics 2012;130:e865-871.

17 Klein D, De Toia D, Weber S, et al: Effects of a low threshold health promotion intervention on the BMI in preschool children under consideration of parental participation. J Clin Nutr Metab 2010;5:e125-e131.

18 Summerbell C, Moore J, Vögele C, et al: Evidence-based recommendations for the development of obesity prevention programs targeted at preschool children. Obes Rev 2012;13:129-132. 
Weihrauch-Blüher et al.: Current Guidelines for Obesity Prevention in Childhood and Adolescence

19 Koletzko B, Armbruster M, Bauer C, et al: Nutrition and physical activity in children from 1-3 years old. Recommendations by the network 'Healthy Start - Young Family Network' (in German). Monatsschr Kinderheilkd 2013;13:1-16.

20 Arenz S, Ruckerl R, Koletzko B, et al: Breast-feeding and childhood obesity - a systematic review. Int J Obes Relat Metab Disord 2004;28:1247-1256.

21 Evelein A, Geerts C, Visseren F, et al: The association between breastfeeding and the cardiovascular system in early childhood. Am J Clin Nutr 2011;93:712-718.

-22 Robinson S, Marriott L, Crozier S, et al; Southampton Women's Survey Study Group: Variations in infant feeding practice are associated with body composition in childhood: a prospective cohort study. J Clin Endocrinol Metab 2009;94:2799-2805.

23 Wu T, Chen P: Health consequences of nutrition in childhood and early infancy. Pediatr Neonatol 2009;50: 135-142:

24 Marchi J, Berg M, Dencker A, et al: Risks associated with obesity in pregnancy, for the mother and baby: a systematic review of reviews. Obes Rev 2015;16):621-638.

25 Fiorito L, Marini M, Francis L, et al: Beverage intake of girls at age 5 y predicts adiposity and weight status in childhood and adolescence. Am J Clin Nutr 2009;90:935-942.

-26 Kavey R: How sweet it is: sugar-sweetened beverage consumption, obesity, and cardiovascular risk in childhood. J Am Diet Assoc 2010;110:1456-1460.

-27 Muckelbauer R, Libuda L, Clausen K, et al: A simple dietary intervention in the school setting decreased incidence of overweight in children. Obes Facts 2009;2:282-285.

-28 Skouteris H, Aquila D, Baur L, et al: Physical activity guidelines for preschoolers: a call for research to inform public health policy. Med J Austr 2012;196:174-177.

-29 Tremblay M, Leblanc A, Carson V, et al: Canadian physical activity guidelines for the early years (aged 0-4 years). ApplPhysiol Nutr Metab 2012;37:345-369.

-30 Dietz WJ, Gortmaker S: Do we fatten our children at the television set? Obesity and television viewing in children and adolescents. Pediatrics 1985;75:807-812.

31 Wahi G, Parkin P, Beyene J, et al: Effectiveness of interventions aimed at reducing screen time in children: a systematic review and meta-analysis of randomized controlled trials. Arch Pediatr Adolesc Med 2011;165: 979-986.

-32 Graf C, Beneke R, Bloch W, et al: Recommendations for promoting physical activity for children and adolescents in Germany. A consensus statement. Obes Facts 2014;7:178-190.

33 Hoelscher D, Kirk S, Ritchie L, et al: Position of the Academy of Nutrition and Dietetics: interventions for the prevention and treatment of pediatric overweight and obesity. J Acad Nutr Diet 2013;113:1375-1394.

-34 Sobol-Goldberg S, Rabinowitz J, Gross R: School-based obesity prevention programs: a meta-analysis of randomized controlled trials. Obesity (Silver Spring) 2013;21:2422-2428.

-35 Muller MJ, Danielzik S, Pust S: School- and family-based interventions to prevent overweight in children. Proc Nutr Soc 2005; 64:249-254.

-36 Tudor-Locke C, Craig C, Beets M: How many steps/day are enough? for children and adolescents. Int J Behav Nutr Phys Act 2011;8:78.

37 Libuda L, Alexy U, Sichert-Hellert W, et al: Pattern of beverage consumption and long-term association with body-weight status in German adolescents - results from the DONALD study. Br J Nutr 2008;99:1370-1379.

-38 Haynos A, O’Donohue W: Universal childhood and adolescent obesity prevention programs: review and critical analysis. Clin Psychol Rev 2012;32:383-399.

-39 Zhou Y, Emerson J, Levine R, et al: Childhood obesity prevention interventions in childcare settings: systematic review of randomized and nonrandomized controlled trials. Am J Health Promot 2013;28:e92-103.

40 Hesketh K, Campbell K: Interventions to prevent obesity in 0-5 year olds: an updated systematic review of the literature. Obesity (Silver Spring) 2010;18:27-35.

-41 Logan S, Robinson L, Wilson A, et al: Getting the fundamentals of movement: a meta-analysis of the effectiveness of motor skill interventions in children. Child Care Health Dev 2 2012;38:305-315.

42 Harris K, Kuramoto L, Schulzer M, et al: Effect of school-based physical activity interventions on body mass index in children: a meta-analysis. CMAJ 2009;180:719-726.

-43 Silveira J, Taddei J, Guerra P, et al: The effect of participation in school-based nutrition education interventions on body mass index: a meta-analysis of randomized controlled community trials. Prev Med 2013;56:237-243.

44 Lavelle H, Mackay D, Pell J: Systematic review and meta-analysis of school-based interventions to reduce body mass index. J Public Health (Oxf) 2012;34:360-369-

-45 Simon C, Shweitzer B, Oujaa M, et al: Successful overweight prevention in adolescents by increasing physical activity: a 4-year randomized controlled intervention. Int J Obes 2008;32:1489-1498.

-46 Singh A, Chin A, Paw M, et al: Dutch obesity intervention in teenagers: Effectiveness of a school-based program on body composition and behavior. Arch Pediatr Adolesc Med 2009;163:309-317.

47 Gortmaker S, Peterson K, Wiecha J, et al: Reducing obesity via a school-based interdisciplinary intervention among youth: Planet Health. Arch Pediatr Adolesc Med 1999;153:409-418.

-48 Swinburn B, Egger G, Raza F: Dissecting obesogenic environments: the development and application of a framework for identifying and prioritizing environmental interventions for obesity. Prev Med 1999;29:563570. 
Weihrauch-Blüher et al.: Current Guidelines for Obesity Prevention in Childhood and Adolescence

49 Gose M, Plachta-Danielzik S, Willié B, et al: Longitudinal influences of neighbourhood built and social environment on children's weight status Int J Environ Res Public Health 2013;10:5083-5096.

50 Bleich S, Segal J, Wu Y, et al: Systematic review of community-based childhood obesity prevention studies. Pediatrics 2013;132:e201-210.

51 Lipek T, Igel U, Gausche R, et al: Obesogenic environments: environmental approaches to obesity prevention. J Pediatr Endocrinol Metab 2015;28:485-495.

-52 Effertz T, Garlichs D, Gerlach S, et al: Wirkungsvolle Prävention chronischer Krankheiten: Strategiepapier der NCD-Allianz zur Primärprävention. Präv Gesundheitsf 201510:95-100.

53 Kromeyer-Hauschild K, Dortschy R, Stolzenberg H, et al: Nationally representative waist circumference percentiles in German adolescents aged 11.0-18.0 years. Int J Pediatr Obes 2011;6:e129-137.

-54 Kromeyer-Hauschild K, Wabitsch M, Kunze D, et al: Perzentile für den Body-mass-Index für das Kindes- und Jugendalter unter Heranziehung verschiedener deutscher Stichproben. Percentiles of body mass index in children and adolescents evaluated from different regional German cohorts (in German). Monatsschr Kinderheilkd 2001;149:807-818. 